\title{
Dissolved air flotation of surface water for spiral-wound module nanofiltration pre-treatment
}

\author{
Vítor Geraldes $^{\mathrm{a}^{*}}$, Aykut Anil ${ }^{\mathrm{a}}$, Maria Norberta de Pinho ${ }^{\mathrm{a}}$, Elizabeth Duarte ${ }^{\mathrm{b}}$ \\ ${ }^{a}$ Department of Chemical and Biological Engineering, Instituto Superior Técnico, 1049-001 Lisbon, Portugal \\ Tel.+351 (21) 841-7511; Fax: +351 (21) 849-9242; email: vitor.geraldes@ist.utl.pt \\ ${ }^{b}$ Department of Agricultural and Environmental Chemistry, Instituto Superior de Agronomia, \\ 1349-017 Lisbon, Portugal
}

Received 27 April 2007; Accepted 3 October 2007

\begin{abstract}
Bench-scale dissolved air flotation (DAF) of Tagus River surface water (Valadas, Portugal) was investigated as pre-treatment for spiral-wound module nanofiltration (SWNF). Before the DAF, a coagulation/flocculation of the surface water was performed using aluminium sulphate, ferric chloride and chitosan coagulants and several commercial coagulant aids. The coagulation/flocculation experiments were carried with $2 \mathrm{~L}$ of surface water in a jartest equipment at room temperature. The DAF performance to remove colloidal matter and suspended solids was evaluated through the measurement of the silt density index (SDI) and the modified fouling index (MFI) of the treated water. The air saturation pressure was varied between 300 and $600 \mathrm{kPa}$ and the recycle ratio between 5 and $50 \%$. The DAF without coagulation/flocculation was not effective in the reduction of both the SDI and MFI, even at a high DAF recycle ratio of $50 \%$. The use of coagulants improved the DAF efficacy in reducing the fouling indexes and, for the optimal operating conditions, the MFI of the treated water was reduced by more than one order of magnitude. However, it was not possible to obtain treated water with SDI and MFI values below the recommended ones for SWNF. Further filtration of the DAF treated water with a 5 micron capsule filter was necessary to reduce the SDI below 5\%/min and the MFI below $10 \mathrm{~s} / \mathrm{l}^{2}$. The integration of DAF with another process that removes the residual suspended solids and colloidal matter is, therefore, necessary to provide a good pretreatment for the SWNF of Tagus River surface water.
\end{abstract}

Keywords: Dissolved air flotation; Spiral-wound module; Nanofiltration; Coagulation/flocculation; SDI; MFI

\section{Introduction}

Nanofiltration has been introduced into the field of water treatment to provide a water quality

*Corresponding author. superior to that obtained by conventional treatments [1-4]. However, when treating surface water, nanofiltration with spiral-wound modules (spiral-wound module nanofiltration, SWNF) requires an elaborate pre-treatment in order to 
prevent membrane fouling and to allow long operation times without cleaning [2,5]. The main objective of the pretreatment is to remove particulate matter, which is constituted by particles, colloids and microorganisms, that is the cause of particulate fouling (e.g., [6,7]). Usually, the conventional pre-treatment is a process involving coagulation/flocculation, sedimentation and media filtration, which has a high impact on the final cost of the drinking water. According to Gorenflo et al. [8], the costs for pre-treatment are estimated to be in the same range as the costs for the SWNF process itself. For this reason, the intensification of the pre-treatment process is an important step to reduce the costs of the SWNF of surface water.

In this study, dissolved air flotation (DAF) of Tagus River surface water, collected in Valadas (Portugal), at a few kilometres from the river estuary, was investigated as alternative pretreatment for SWNF. In this region, due to the proximity of the river estuary and due to existence of a large surface water reservoir, the disposal of nanofiltration concentrates should not constitute a severe problem [9]. For this reason, in this context, SWNF can be regarded as a viable alternative to produce high quality drinking water.

DAF is a mature technology that has been extensively used with success in water treatment. The main advantages of this separation process are [10]: (1) capacity to capture between $80 \%$ and $90 \%$ of very fine particulate matter, (2) capability of reducing the water turbidity below 1 NTU, (3) reduced chemicals usage and (4) high surface loading rate/small compact plant. These features make DAF a good candidate to replace, with technical and economic advantages, totally or partially the conventional pre-treatment process for SWNF. The present work aims to investigate that at bench scale. For DAF, the air saturation pressure is commonly in the range between 270 and $510 \mathrm{kPa}$ and the recycle ratio, defined as the ratio of the recirculation flow rate of air-saturated water by the inlet water flowrate, is in the range between 10 and 120\% [11]. DAF is integrated usually with coagulation/flocculation of the feed water to generate flocks that are attached more strongly to the rising air bubbles.

In this work, the DAF efficacy in the removal of colloidal and particulate matter has been evaluated through the measurement of both the silt density index (SDI) (Standard Test Method ASTM D4189-82) and the modified fouling index (MFI) [12] of the treated water. These SDI and MFI indexes are used commonly to evaluate if the concentration of colloidal and particulate matter of the water is adequate for SWNF. Most membrane manufactures recommend that the SDI should be in the range between 3 and $5 \% / \mathrm{min}$, while the MFI should be lower than $10 \mathrm{~s} / \mathrm{l}^{2}$ [13]. It should be mentioned, however, that the recommendations based on these indexes should be respected, but possible fouling problems can occur even when the indexes values are considered acceptable [14].

\section{Materials and methods}

\subsection{Materials}

The surface water was collected from the Tagus River, just before the river estuary, in the region of Valadas (ca. $40 \mathrm{~km}$ from Lisbon, Portugal). A typical composition of the surface water in the summer is displayed in Table 1 . The water was stored in full tanks of $20 \mathrm{~L}$ at room temperature during one or two days until being used.

Aluminium sulphate from Riedel-de Haen (Seelze, Germany), ferric chloride pro Analysis from Merck (Whitehouse Station, USA) and chitosan from Pronova (Lysaker, Norway) were used as coagulants and the following coagulation aids products were tested: Praestol 187-K, Praestol 185-K and Praestol 190-K, from Stockhausen (Krefeld, Germany) and Magnofloc 1597, from Ciba (Basel, Switzerland). Aqueous solutions of $10 \mathrm{~g} / \mathrm{L}$ of aluminium sulphate, $10 \mathrm{~g} / \mathrm{L}$ of ferric chloride and $1 \mathrm{~g} / \mathrm{L}$ of chitosan were 
Table 1

Composition of the surface water from the Tagus River collected on 11 July 2005 [15]

\begin{tabular}{ll}
\hline $\mathrm{pH}$ & 7.7 \\
Conductivity, $\mu \mathrm{S} / \mathrm{cm}$ & 647 \\
Turbidity, NTU & 16.4 \\
Non-purgeable organic carbon, $\mathrm{mg} / \mathrm{L}$ & 3.3 \\
Adsorbable organic halogens, $\mu \mathrm{g} / \mathrm{L}$ & 235 \\
Ions, mg/L & \\
$\quad \mathrm{Cl}^{-}$ & 110 \\
$\mathrm{SO}_{4}^{2-}$ & 143 \\
$\mathrm{HCO}_{3}^{-}$ & 135 \\
$\mathrm{Na}^{+}$ & 85 \\
$\mathrm{~K}^{+}$ & 6 \\
$\mathrm{Ca}^{2+}$ & 55.5 \\
$\mathrm{Mg}^{2+}$ & 16 \\
$\mathrm{Fe}^{2+}$ & 0.05 \\
\hline
\end{tabular}

prepared for subsequent use in the surface water coagulation/flocculation. The aqueous solution of chitosan was prepared by slowly mixing $1 \mathrm{~g}$ of chitosan with $1 \mathrm{~L}$ of water during 2 hours at room temperature and with periodic addition of diluted hydrochloric acid to keep the $\mathrm{pH}$ at 4.0.

\subsection{Coagulation/flocculation}

The coagulation/flocculation experiments were carried out with $2 \mathrm{~L}$ of surface water in a jar-test equipment (model Flocumatic supplied by J.P. Selecta, Barcelona, Spain) at room temperature. After adjustment of the surface water $\mathrm{pH}$, using diluted hydrochloric acid, the required volume of coagulant concentrated solution was rapidly mixed with the surface water at $200 \mathrm{rpm}$ during $1 \mathrm{~min}$. After this procedure, the mixing rate was reduced to $60 \mathrm{RPM}$ during $20 \mathrm{~min}$, in order to promote the growth of the flocs.

\subsection{Dissolved air flotation and filtration}

The DAF experiments were performed in a bench-scale flotation cell described elsewhere [16]. This cell had a pressurized chamber with a volume of ca. $10 \mathrm{~L}$ that discharged the airsaturated water through a needle valve into a calibrated column with $7 \mathrm{~cm}$ diameter, $90 \mathrm{~cm}$ height and with a volume of $3.5 \mathrm{l}$. The pressurized chamber was initially filled with deionised water. After that, compressed air was injected into the water and the pressurized chamber was vigorous agitated during $5 \mathrm{~min}$ to ensure that the water became saturated with air. After this procedure, a volume $V_{1}$ of air-saturated water was discharged slowly through a needle valve into the calibrated column with a volume $V_{2}=2 \mathrm{~L}$ of river water. The ratio $V_{1} / V_{2}$ corresponds to the DAF recycle ratio in continuous operation and was varied between 10 and 50\%. After injecting the volume $V_{1}$ of air-saturated water into the column, the flotation was carried on during 10 minutes. The clarified water was then removed at the column bottom through a sampling valve.

Disposable filter capsules Polycap HD from Whatman (Springfield Mill, UK), with pore sizes of $1 \mu \mathrm{m}$ and $5 \mu \mathrm{m}$ and a filter media area of $805 \mathrm{~cm}^{2}$ were used for filtration of the DAF treated water.

\subsection{SDI and MFI measurement}

The DAF performance was evaluated through the measurement of both silt density index (SDI) (ASTM D4 189) and modified fouling index (MFI) [11]. To measure both fouling indexes, the treated water was dead-end filtrated at $207 \mathrm{kPa}$, through a $47 \mathrm{~mm}$ diameter membrane with a pore size of 0.45 pm (HTTP 4700 Isopore membrane filters, Millipore). The volume of water permeated through the microfiltration membrane was measured manually as a function of time during 6 minutes, at several time intervals. The SDI was computed by

$$
S D I=\frac{100\left(1-\frac{V_{f}}{V_{i}}\right)}{5 \mathrm{~min}}
$$




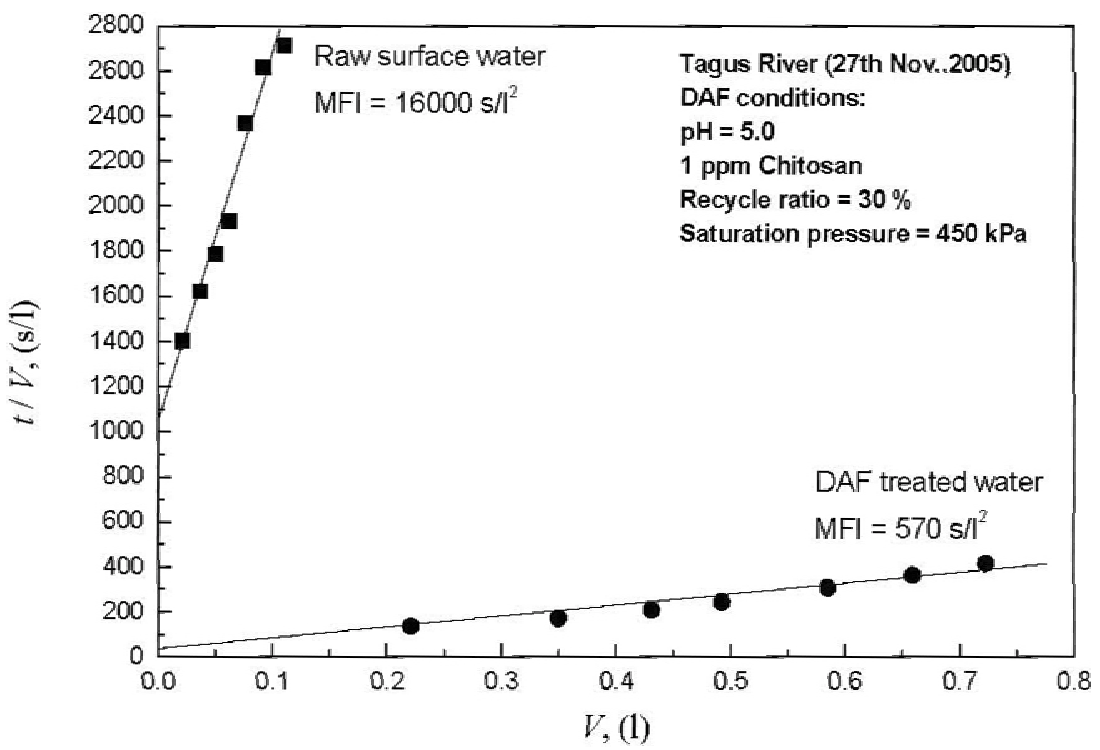

Fig. 1. Typical MFI curves for raw surface water and DAF treated water.

where $V_{i}$ is the volume of permeate obtained during the second minute of microfiltration and $V_{f}$ is the volume obtained during the last minute. The units of the SDI are \% flux reduction $/ \mathrm{min}$.

The MFI was obtained through the fitting of the following equation [11]:

$$
t / V=\alpha+M F I \cdot V
$$

to the $t / V$ versus $V$ data, where $t$ is the filtration time and $V$ is the total volume of water that passed through the microfiltration membrane. A linear correlation was obtained for all the experiments whenever the data measurement was performed 1 min after the beginning of the microfiltration. Below this stabilization time, a strong non-linear behaviour between $t / V$ and $V$ was observed due, probably, to the strong initial increase of the membrane resistance due to pore blocking. The MFI is proportional to the specific resistance of the cake layer, which in turn depends on the total concentration of particulate matter in the feed solution [11]. Therefore, the MFI is a good indicator of the total concentration of particulate matter of the surface water. Two typical MFI determination curves, for raw water and for DAF treated water using $1 \mathrm{mg} / \mathrm{L}$ of chitosan as coagulant, are displayed in Fig. 1. As shown in this figure, a linear correlation between $t / V$ vs. $V$ is observed for both the treated and untreated water.

\section{Results and discussion}

The raw Tagus surface water is characterized by having high values of MFI and SDI, as shown in Table 2, for several water samples collected between September and December 2005. The MFI is at least 3 orders of magnitude higher that the maximum value of $10 \mathrm{~s} / \mathrm{l}^{2}$ recommended for SWNF and the SDI is about 4 times higher than the recommended value of $5 \% / \mathrm{min}$. This means that an adequate pre-treatment of the surface water is required before the SWNF.

The effect of the DAF operating conditions on the MFI and SDI of the treated water is displayed in Table 3, for coagulation/flocculation with aluminium sulphate. The raw water used had an 
Table 2

MFI and SDI of untreated Tagus River surface water

\begin{tabular}{lcl}
\hline Collection date & MFI $\left(\mathrm{s} / \mathrm{l}^{2}\right)$ & SDI (\%) \\
\hline 24 Sep. 2005 & 6,970 & 19.3 \\
25 Oct. 2005 & 9,100 & 18.1 \\
27 Nov. 2005 & 14,900 & 19.4 \\
14 Dec. 2005 & 6,540 & 19.4 \\
\hline
\end{tabular}

SDI of $19.3 \% / \mathrm{min}$ which was very high, compared with the maximum value of $5 \% / \mathrm{min}$, recommended for normal operation of SWNF. Without coagulation/flocculation and, even for the highest values of saturation pressure and recycle ratio investigated, both the MFI and SDI do not decrease substantially after DAF. In these conditions, the DAF does not reduce the fouling potential of the treated water. After coagulation/ flocculation of the surface water with aluminium sulphate, however, both the MFI and SDI reduce significantly. For the range of operating conditions investigated, the minimum MFI value of $96 \mathrm{~s} / \mathrm{l}^{2}$ was obtained for a saturation pressure of $600 \mathrm{kPa}$, at $\mathrm{pH} 6.0$ and with an aluminium sulphate concentration of $40 \mathrm{mg} / \mathrm{L}$. Furthermore, the data displayed in Table 3 shows that, for the range of operating conditions studied, the MFI and SDI are not very sensitive to the variation of recycle ratio and saturation pressure. At $\mathrm{pH} 6$ the MFI decreased with the aluminium sulphate concentration, while at $\mathrm{pH} 5$ the opposite behaviour was observed. The final MFI and SDI values of the DAF treated water using aluminium sulphate coagulant, at the optimal operating conditions were, however, still much higher than the recommended values for SWNF. It should, however, be underlined that under these operating conditions DAF can reduce the MFI of the treated water - and hence the total concentration of particulate matter - by at least two orders of magnitude.

For the DAF of the surface water using ferric chloride coagulation/flocculation, Table 4 dis- plays the effect of the saturation pressure, ferric chloride concentration and coagulant aid type and concentration on the MFI and SDI of the treated water. The SDI of the surface water used in these experiments was $18.1 \% / \mathrm{min}$, which was again very high for SWNF. Without using coagulant aids, the results show that both MFI and SDI decreased with the increase of the ferric chloride concentration, exhibiting minimum values at 40 $\mathrm{mg} / \mathrm{L}$, for all the saturation pressures tested. The minimum values of the MFI and SDI were obtained at a saturation pressure of $450 \mathrm{kPa}$.

For the optimum operating conditions with ferric chloride coagulation/flocculation, both SDI and MFI of the treated water were still very high for a normal operation of SWNF. To increase the DAF performance, several polymeric coagulants aids commonly used in water treatment were tested. The results, displayed in the last rows of Table 4, show that the only coagulant aid that improved the DAF performance was the Praestol 187-K. The decrease observed in the SDI and MFI with the use of this coagulant was, however, not sufficient to make the DAF process alone a good pre-treatment for SWNF. In fact, the minimum value of SDI (15.4\%/min) obtained at a Praestol 187-K concentration of $1 \mathrm{mg} / \mathrm{L}$, was still very high for SWNF. For this range of operating conditions, the DAF with ferric chloride coagulation/flocculation under optimal operating conditions, therefore, does not provide the adequate pre-treatment for SWNF of the Tagus River surface water. Despite of that, the DAF process operating under the optimal conditions was adequate to reduce the MFI of the treated water by one order of magnitude.

The effect of the DAF operating conditions on the MFI and SDI of the treated water, for coagulation/flocculation with chitosan, is displayed in Table 5. The first set of data, which displays the effect of the chitosan concentration on the MFI and SDI, shows that the optimal concentration was $1 \mathrm{mg} / \mathrm{L}$. The increase of the chitosan concentration above this value increased both the MFI 
Table 3

Effect of DAF operating conditions on the MFI and SDI of the treated water, for coagulation/flocculation with aluminium sulphate $^{\mathrm{a}}$

\begin{tabular}{|c|c|c|c|c|c|}
\hline Saturation pressure $(\mathrm{kPa})$ & $\mathrm{pH}$ & Recycle ratio (\%) & Aluminium sulphate conc. (mg/L) & $\operatorname{MFI}\left(\mathrm{s} / \mathrm{l}^{2}\right)$ & SDI (\%/min) \\
\hline 600 & 6 & 50 & - & 5050 & 17.9 \\
\hline \multirow[t]{5}{*}{600} & 6 & 5 & 40 & 129 & 14.1 \\
\hline & & 10 & & 178 & 13.8 \\
\hline & & 20 & & 161 & 14 \\
\hline & & 30 & & 154 & 13.7 \\
\hline & & 40 & & 249 & 14 \\
\hline \multirow[t]{3}{*}{600} & 5 & 10 & 10 & 365 & 14.8 \\
\hline & & & 20 & 698 & 15.2 \\
\hline & & & 40 & 1720 & 16.8 \\
\hline \multirow[t]{3}{*}{600} & 6 & 10 & 10 & 694 & 12.7 \\
\hline & & & 20 & 248 & 14.7 \\
\hline & & & 40 & 96 & 13.4 \\
\hline 300 & 6 & 20 & 40 & 182 & 13.2 \\
\hline 450 & & & & 133 & 13.5 \\
\hline 600 & & & & 161 & 14 \\
\hline
\end{tabular}

${ }^{a}$ Tagus River surface water was collected on 24 Sep 2005. MFI and SDI of the raw water at pH 7 were $6970 \mathrm{~s} / \mathbf{l}^{2}$ and $19.3 \% /$ min, respectively.

Table 4

Effect of DAF operating conditions on the MFI and SDI of the treated water, for coagulation/flocculation with ferric chloride $^{\mathrm{a}}$

\begin{tabular}{llllrl}
\hline $\begin{array}{l}\text { Saturation pressure } \\
(\mathrm{kPa})\end{array}$ & $\begin{array}{l}\text { Ferric chloride conc. } \\
(\mathrm{mg} / \mathrm{L})\end{array}$ & $\begin{array}{l}\text { Coagulant } \\
\text { aid }\end{array}$ & $\begin{array}{l}\text { Coag. aid conc. } \\
(\mathrm{mg} / \mathrm{L})\end{array}$ & $\begin{array}{r}\text { MFI } \\
\left(\mathrm{s} / \mathrm{l}^{2}\right)\end{array}$ & $\begin{array}{l}\text { SDI } \\
(\% / \mathrm{min})\end{array}$ \\
\hline 300 & 10 & - & - & 4,390 & 18 \\
& 20 & - & - & 1,440 & 17.2 \\
& 40 & - & - & 620 & 16.2 \\
450 & - & - & 2,230 & 17.3 \\
& 10 & - & - & 1,680 & 17.2 \\
600 & 20 & - & - & 580 & 15.6 \\
& 40 & - & - & 2,900 & 17.1 \\
& 10 & - & - & 1,160 & 16.8 \\
450 & 20 & Praestol 187-K & 0.1 & 644 & 16.3 \\
& 40 & & 0.5 & 430 & 15.5 \\
& 40 & & 1 & 380 & 15.4 \\
& & Praestol 185-K & 1 & 42,700 & 17.8 \\
& & Praestol 190-K & 1 & 5,060 & 16.4 \\
& & Magnofloc 1597 & 1 & 61,000 & 18.3 \\
\hline
\end{tabular}

${ }^{a}$ Tagus River surface water was collected on 25 Oct. 2005. MFI and SDI of the raw water at pH 8 were $9100 \mathrm{~s} / \mathrm{l}^{2}$ and $18.1 \% / \mathrm{min}$, respectively. DAF was performed at $\mathrm{pH} 8.0$ with a recycle ratio of $30 \%$. 
Table 5

Effect of DAF operating conditions on the MFI and SDI of the treated water, for coagulation/flocculation with chitosan ${ }^{\mathrm{a}}$

\begin{tabular}{|c|c|c|c|c|c|}
\hline Saturation pressure $(\mathrm{kPa})$ & $\mathrm{pH}$ & Recycle ratio (\%) & Coagulant conc. (mg/L) & MFI (s/2²) & SDI (\%/min) \\
\hline \multirow[t]{5}{*}{450} & 7.3 & 30 & 0.5 & 1000 & 18.2 \\
\hline & & & 1 & 470 & 17.9 \\
\hline & & & 2 & 750 & 18.1 \\
\hline & & & 5 & 6200 & 18.7 \\
\hline & & & 10 & $1 e+05$ & 19.3 \\
\hline \multirow[t]{3}{*}{450} & 5 & 30 & 1 & 570 & 18.5 \\
\hline & 6 & & & 760 & 18.5 \\
\hline & 8 & & & 3800 & 18 \\
\hline 300 & 5 & 30 & 1 & 950 & 18.3 \\
\hline 450 & & & & 570 & 18.5 \\
\hline 600 & & & & 345 & 18.5 \\
\hline \multirow[t]{3}{*}{600} & 5 & 10 & 1 & 550 & 18.3 \\
\hline & & 20 & & 450 & 18.2 \\
\hline & & 40 & & 400 & 18.5 \\
\hline
\end{tabular}

aTagus River surface water was collected on 27 Nov. 2005. MFI and SDI of the raw water at $\mathrm{pH} 7$ were 14,932 l/s ${ }^{2}$ and $19.4 \% / \mathrm{min}$, respectively.

and the SDI of the treated water. The saturation pressure, the recycle ratio and $\mathrm{pH}$ did not have significant influence on both the MFI and SDI. Under the optimal operating conditions, the DAF with chitosan coagulation/flocculation reduced the SDI of the treated water only to $17.9 \% / \mathrm{min}$. Once again, the DAF was capable to reduce the MFI by more than one order of magnitude, but it was not sufficient to provide the necessary pretreatment for SWNF.

The overall analysis of the data displayed in Tables 3-5 shows that the MFI is a better indicator for measuring the performance of the DAF than the SDI, because the MFI is very sensitive to the operating conditions, while the SDI varies only marginally. Furthermore, these results show that, within the range of operating conditions investigated, the DAF with coagulation/ flocculation is not sufficient to bring the SDI and the MFI of the treated water to values compatible with normal operation of SWNF. For this reason, it is necessary to combine DAF with another process, such as media filtration or microfiltration, to reduce to acceptable levels of residual suspended solids and colloidal matter of the treated water. This process integration may prove to be economical because the DAF under the optimal operating conditions can reduce the MFI and, hence the particulate matter concentration, by more than one order of magnitude for coagulation/flocculation with ferric chloride or chitosan and by more than two orders of magnitude for coagulation/flocculation with aluminium sulphate.

The effect of the combination of the DAF with capsule filtration on the MFI and SDI is displayed in Table 6 for coagulation/flocculation with ferric chloride and chitosan. For both coagulants, while the DAF without filtration has almost no effect on the SDI, the combined DAF/filtration sequence reduces that value to $4.2 \% / \mathrm{min}$ with the $5 \mu \mathrm{m}$ filtration, and to a value below $3.8 \% / \mathrm{min}$ with the 
Table 6

Effect of the combination of DAF with capsule filtration on the MFI and SDI of the treated water ${ }^{\mathrm{a}}$

\begin{tabular}{|c|c|c|c|c|}
\hline Pre-treatment & Coagulant & $\mathrm{pH}$ & $\operatorname{MFI}\left(\mathrm{s} / \mathrm{l}^{2}\right)$ & SDI (\%/min) \\
\hline DAF & Ferric chloride (40 mg/L) & 7 & 800 & 18.8 \\
\hline DAF / $1 \mu \mathrm{m}$ filtration & & & 1.9 & 2.7 \\
\hline DAF / $5 \mu \mathrm{m}$ filtration & & & 3 & 4.2 \\
\hline DAF & Chitosan (1 mg/L) & 5 & 260 & 18.4 \\
\hline DAF / $1 \mu \mathrm{m}$ filtration & & & 0.72 & 3.8 \\
\hline DAF / 5 mm filtration & & & 1.65 & 4.2 \\
\hline
\end{tabular}

${ }^{a}$ Tagus River water was collected on 14 Dec. 2005. MFI and SDI of the raw water at pH 7.3 were $6540 \mathrm{l} / \mathrm{s}^{2}$ and $19.4 \% / \mathrm{min}$, respectively. DAF was performed at a saturation pressure of $450 \mathrm{kPa}$, with a recycle ratio of $30 \%$.

$1 \mu \mathrm{m}$ filtration. At the same time, the MFI was reduced by two orders of magnitude when the DAF was combined with filtration. The reduction of the filter pore diameter from $5 \mu \mathrm{m}$ to $1 \mu \mathrm{m}$ improved the reduction of both MFI and SDI, but the coagulant type did not have a strong influence on the final values of the SDI and MFI. These results indicate that the DAF process must be integrated with another treatment, for instance media filtration or microfiltration, that removes the residual suspended solids and colloidal matter with an average particle diameter at least below $5 \mu \mathrm{m}$ in order to obtain MFI and SDI values compatible with normal operation of SWNF of Tagus River surface water.

\section{Concluding remarks}

The effect of the DAF operating conditions on the MFI and SDI of the treated water was investigated in a bench scale for the particular case of Tagus River surface water. The SDI of the untreated surface water was between 18.1 and $19.4 \% / m i n$, which was very high when compared to the typical values between 3 and $5 \% / \mathrm{min}$ recommended by most membrane manufacturers. The DAF without coagulation/flocculation was not effective in the reduction of both the SDI and MFI, even with a recycle ratio of $50 \%$. The use of coagulants improved the DAF efficacy in the reduction the fouling indexes. However, under the optimal conditions for every coagulant tested, it was not possible to achieve SDI and MFI values below the recommended values for SWNF. Further filtration of the DAF treated water with 1 or $5 \mu \mathrm{m}$ capsule filters was necessary to reduce the SDI and MFI to acceptable values. These results indicate that the DAF process, in the range of operating conditions investigated, must be integrated with another treatment that removes the residual suspended particles and colloidal matter, with an average particle diameter below $5 \mu \mathrm{m}$, in order to obtain MFI and SDI values compatible with normal operation of SWNF of Tagus River surface water.

\section{Acknowledgements}

The authors are grateful to the Fundação para a Ciência e a Tecnologia-Portugal for the financial support through Project POCTI/EQU/46875/ 2002) and to the Socrates-Erasmus Exchange program for the financial support of the co-author Aykut Anil.

\section{References}

[1] T. Thorsen, Membrane filtration of humic substances: state of the art, Water Sci. Technol., 40(9) (1999) 105-112. 
[2] B. Cyna, G. Chagneau, G. Bablon and N. Tanghe, Two years of nanofiltration at the Méry-sur-Oise plant, France, Desalination, 147 (2002) 69-75.

[3] I. Mijatovic, M. Matosic, B.H. Cerneha and D. Bratulic, Removal of natural organic matter by ultrafiltration and nanofiltration for drinking water production, Desalination, 169 (2004) 223-230.

[4] V.B. der Bruggen and C. Vandecasteele, Removal of pollutants from surface water and groundwater by nanofiltration: overview of possible applications in the drinking water industry, Environ. Poll., 122 (2003) 435-445.

[5] C.R. Reiss, J.S. Taylor and C. Robert, Surface water treatment using nanofiltration: pilot testing results and design considerations, Desalination, 125 (1999) 97-112.

[6] F.E. Boerlage, M.D. Kennedy, M.P. Aniye, E.M. Abogrean, G. Galjaard and J.C. Schippers, Monitoring particulate fouling in membrane systems, Desalination, 118 (1998) 131-142.

[7] A.R. Costa, M.N. de Pinho and M. Elimelech, Mechanisms of colloidal natural organic matter fouling in ultrafiltration, J. Membr. Sci., 281(1-2) (2006) 716-725.

[8] A. Gorenflo, D. Velázquez-Padón and F.H. Frimmel, Nanofiltration of a German groundwater of high hardness and NOM content: performance and costs, Desalination, 151 (2002) 253-265.
[9] M.M. Nederlof, J.A.M. van Paassen and R. Jong, Nanofiltration concentrate disposal: experiences in The Netherlands, Desalination, 178 (2005) 303-312.

[10] T. Schofield, Dissolved air flotation in drinking water production, Water Sci. Technol., 43(8) (2001) 9-18.

[11] Metcalf \& Eddy, Inc., Wastewater Engineering: Treatment, Disposal, and Reuse, 3rd ed., McGrawHill, New York, 1991.

[12] J.C. Schippers and J. Verdouw, The modified fouling index: a method of determining the fouling characteristics of water, Desalination, 32 (1980) 137-148.

[13] J.S. Taylor, L.K. Sung and K.E. Morris, Predicting colloidal fouling, Internat. Desalination Water Reuse J., 4(3) (1994) 38-42.

[14] S.G. Yiantsios, D. Sioutopoulos and A.J. Karabelas, Colloidal fouling of RO membranes: an overview of key issues and efforts to develop improved prediction techniques, Desalination, 183 (2005) 257-272.

[15] V. Geraldes, M.N. de Pinho, C.M.S. Fonseca and E. Duarte, Spiral-wound module nanofiltration of surface river water, J. E-Water, accepted for publication.

[16] M.N. de Pinho, M. Minhalma, M.J. Rosa and F. Taborda, Integration of flotation/ultrafiltration for treatment of bleached pulp effluent, Pulp Pap. Can., 101(4) (2000) 50-54. 